\title{
Synthesis of Karrikinolide Using the Aldol Type Acetal Addition Reaction
}

Kanade Kirita and Seijiro Hosokawa*

Department of Applied Chemistry, Faculty of Science and Engineering, Waseda University 3-4-1 Ohkubo, Shinjuku-ku, Tokyo 169-8555, Japan

seijiro@waseda.jp

\section{Supporting Information}

\section{Table Contents:}

Comparison of melting point and spectroscopic data of 1 with those reported in a literature S2

${ }^{1} \mathrm{H}$ and ${ }^{13} \mathrm{C}$ NMR Spectra S3-S14 


\section{Comparison of melting point and spectroscopic data of 1 with those reported in a literature}

Table S1. Comparison of the m.p. and spectroscopic data of $\mathbf{1}$ with reported literature.

\begin{tabular}{|c|c|c|c|c|c|}
\hline \multicolumn{2}{|c|}{ m.p. } & \multicolumn{2}{|c|}{${ }^{1} \mathrm{H}$ NMR } & \multicolumn{2}{|c|}{${ }^{13} \mathrm{C}$ NMR } \\
\hline 1 & reported data ${ }^{1)}$ & 1 & reported data $^{1)}$ & 1 & reported data ${ }^{1)}$ \\
\hline \multirow[t]{8}{*}{$118-119^{\circ} \mathrm{C}$} & $118-119^{\circ} \mathrm{C}$ & 1.94 & 1.94 & 7.7 & 7.6 \\
\hline & & 6.51 & 6.52 & 100.3 & 100.2 \\
\hline & & 7.32 & 7.32 & 103.4 & 103.4 \\
\hline & & 7.44 & 7.44 & 126.8 & 126.8 \\
\hline & & & & 139.7 & 139.7 \\
\hline & & & & 142.3 & 142.2 \\
\hline & & & & 148.0 & 148.0 \\
\hline & & & & 171.3 & 171.2 \\
\hline
\end{tabular}

1) Nagase, R.; Katayama, M.; Mura, H.; Matsuo, N.; Tanabe, Y. Tetrahedron Letters, 2008, 49, 4509-4512. 


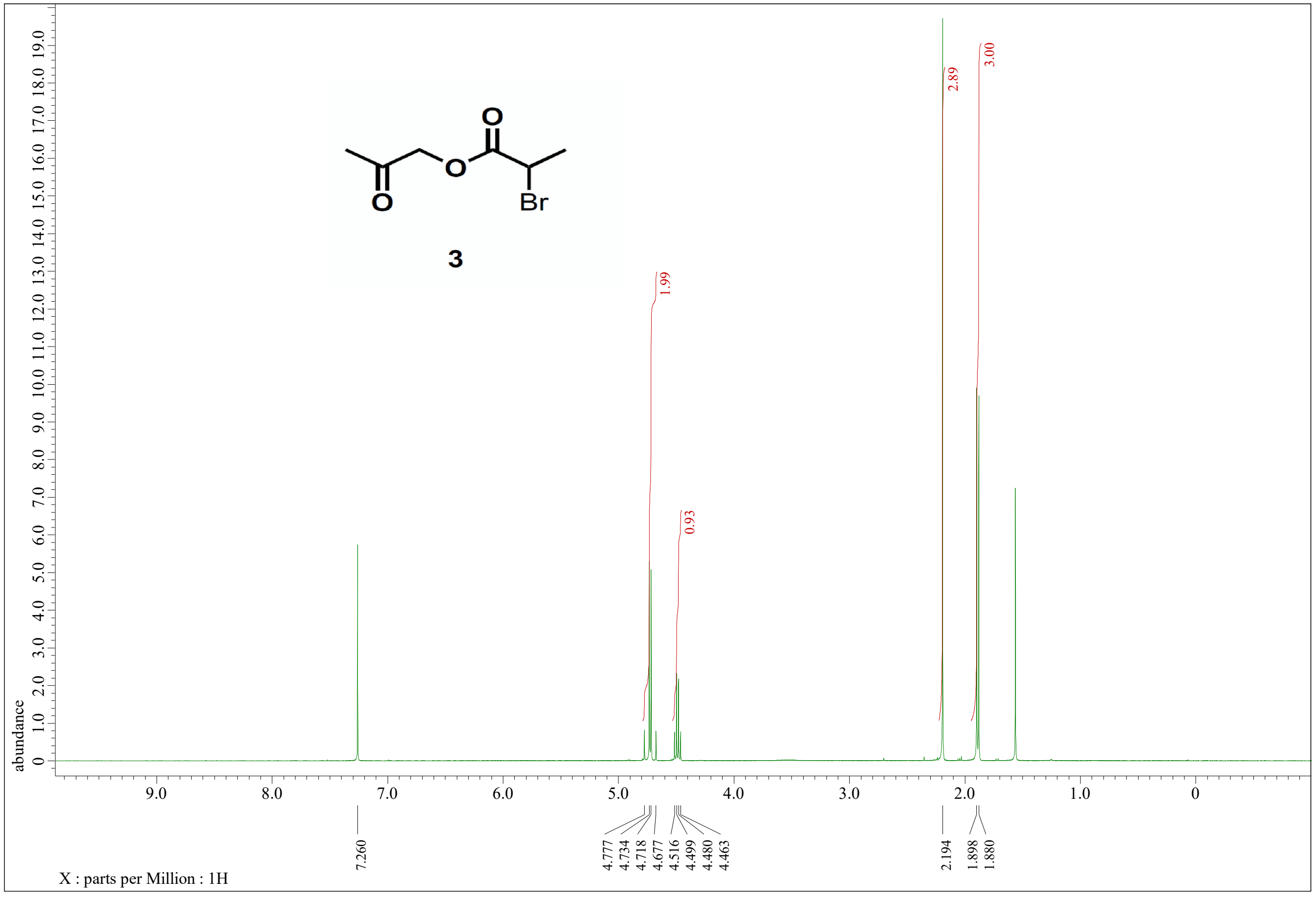




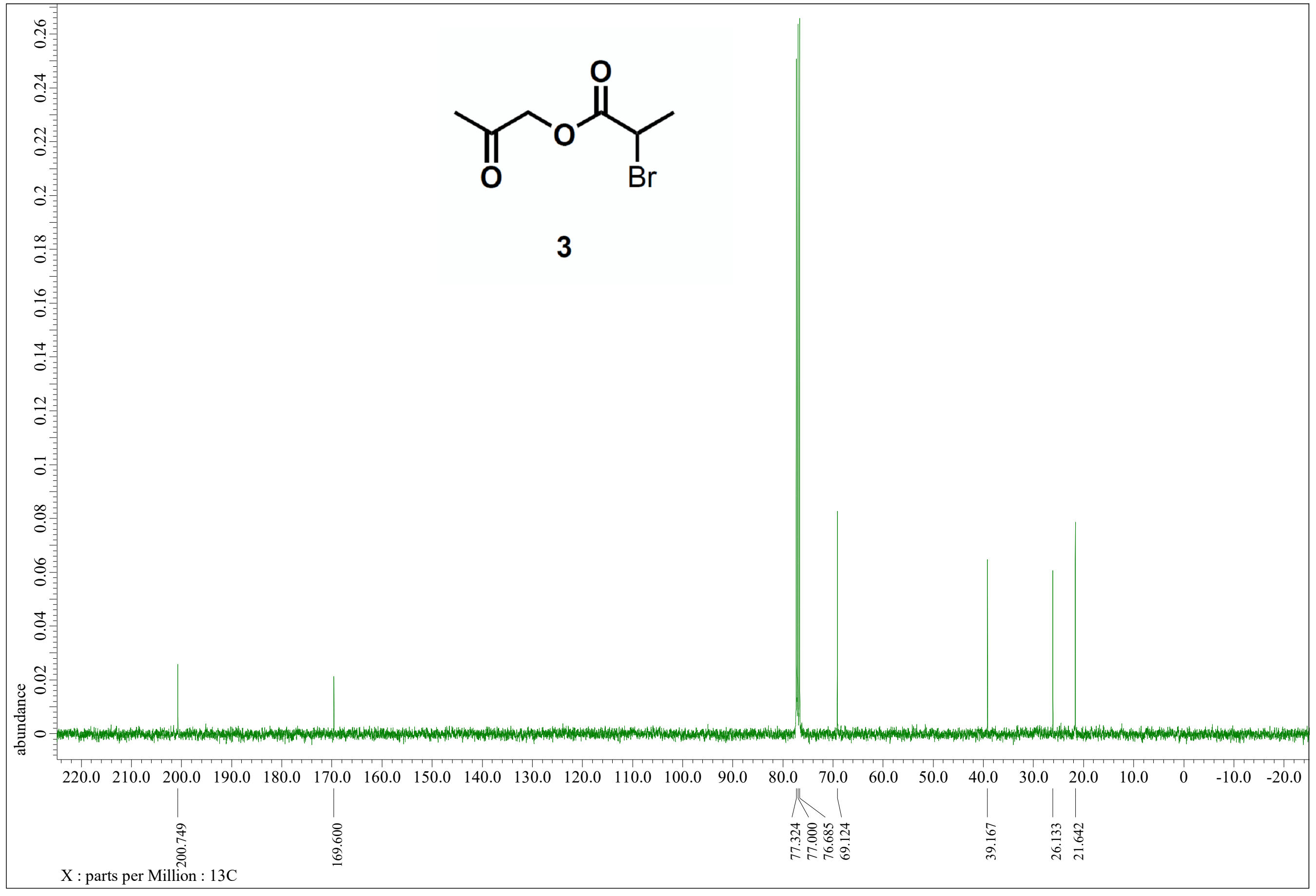




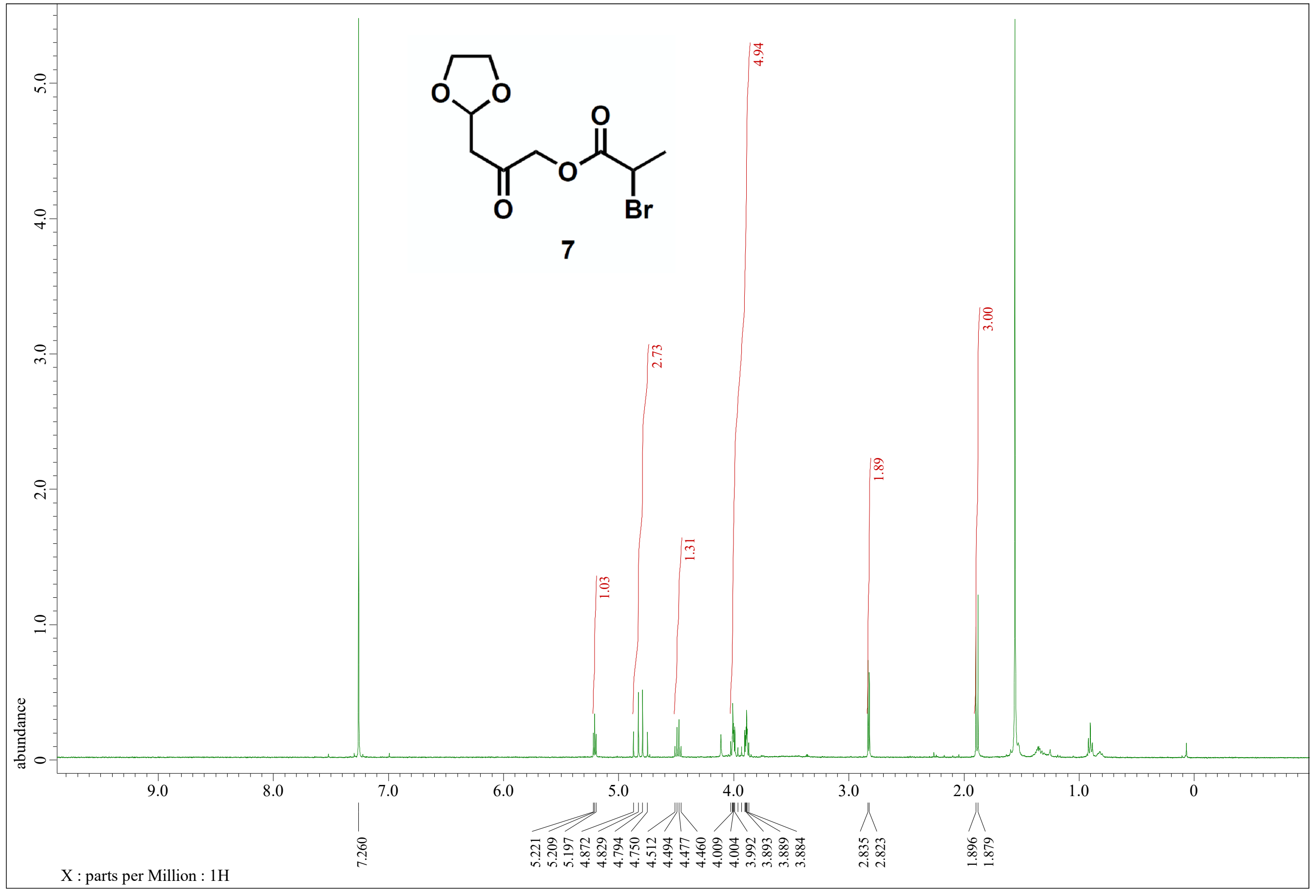




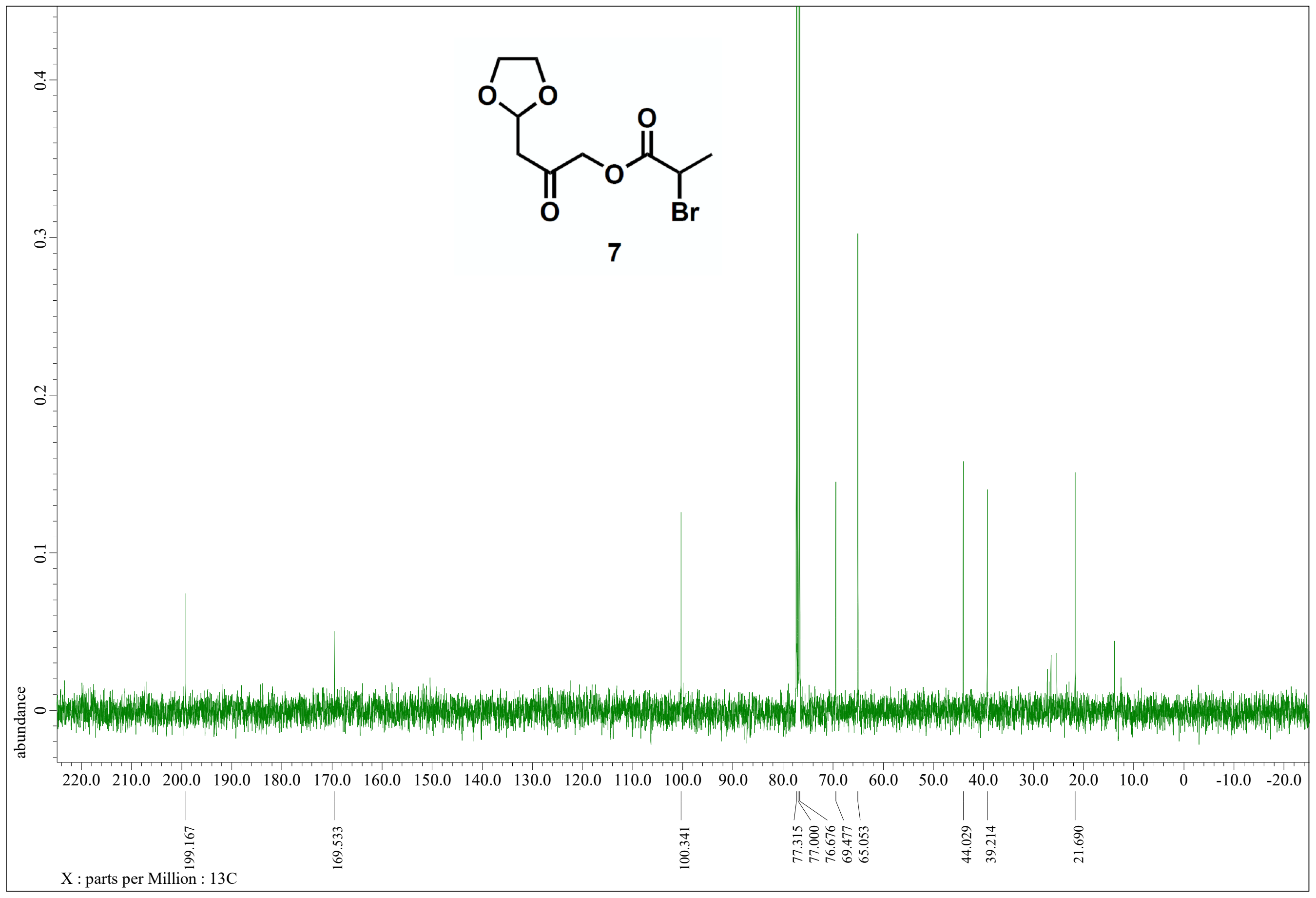




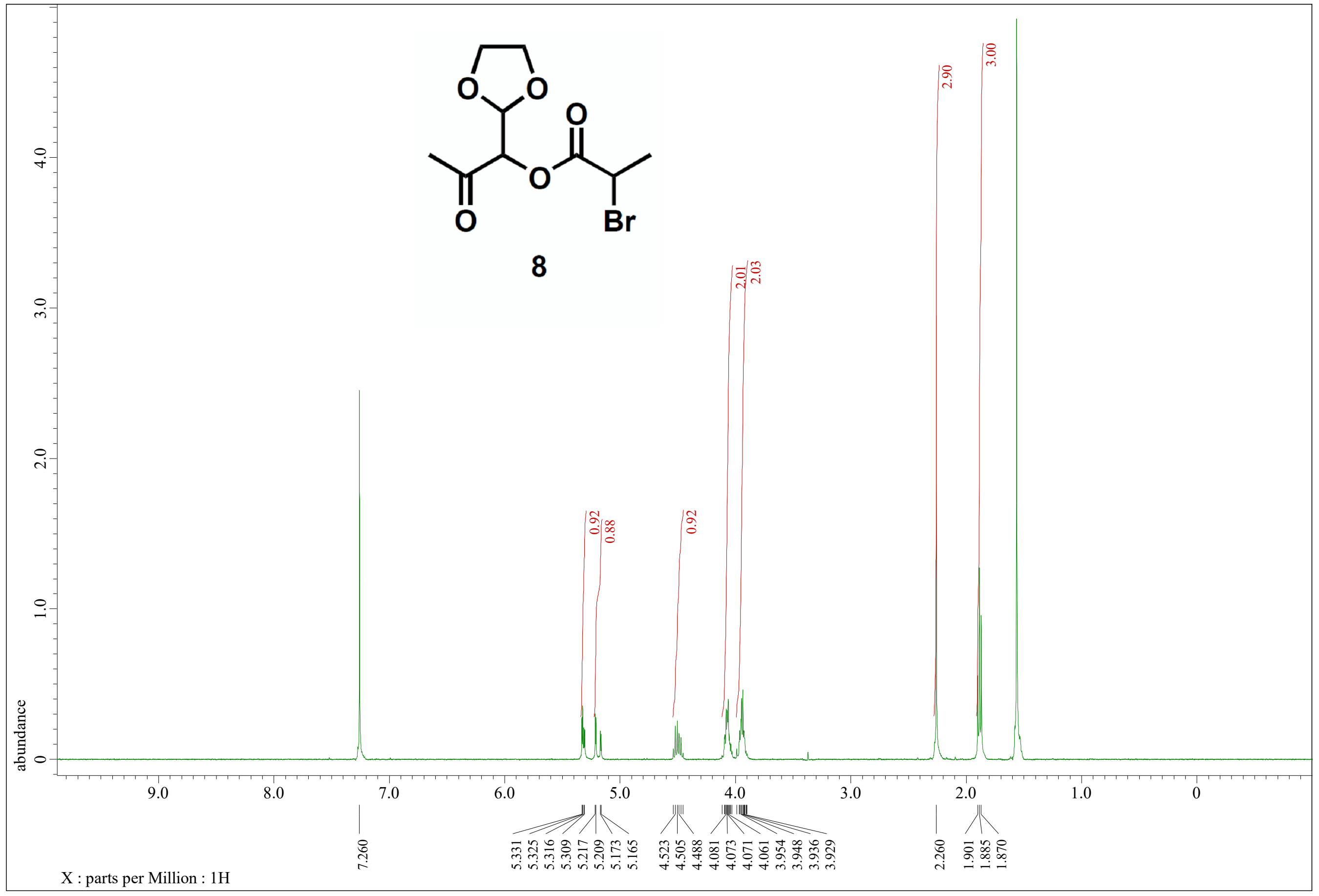




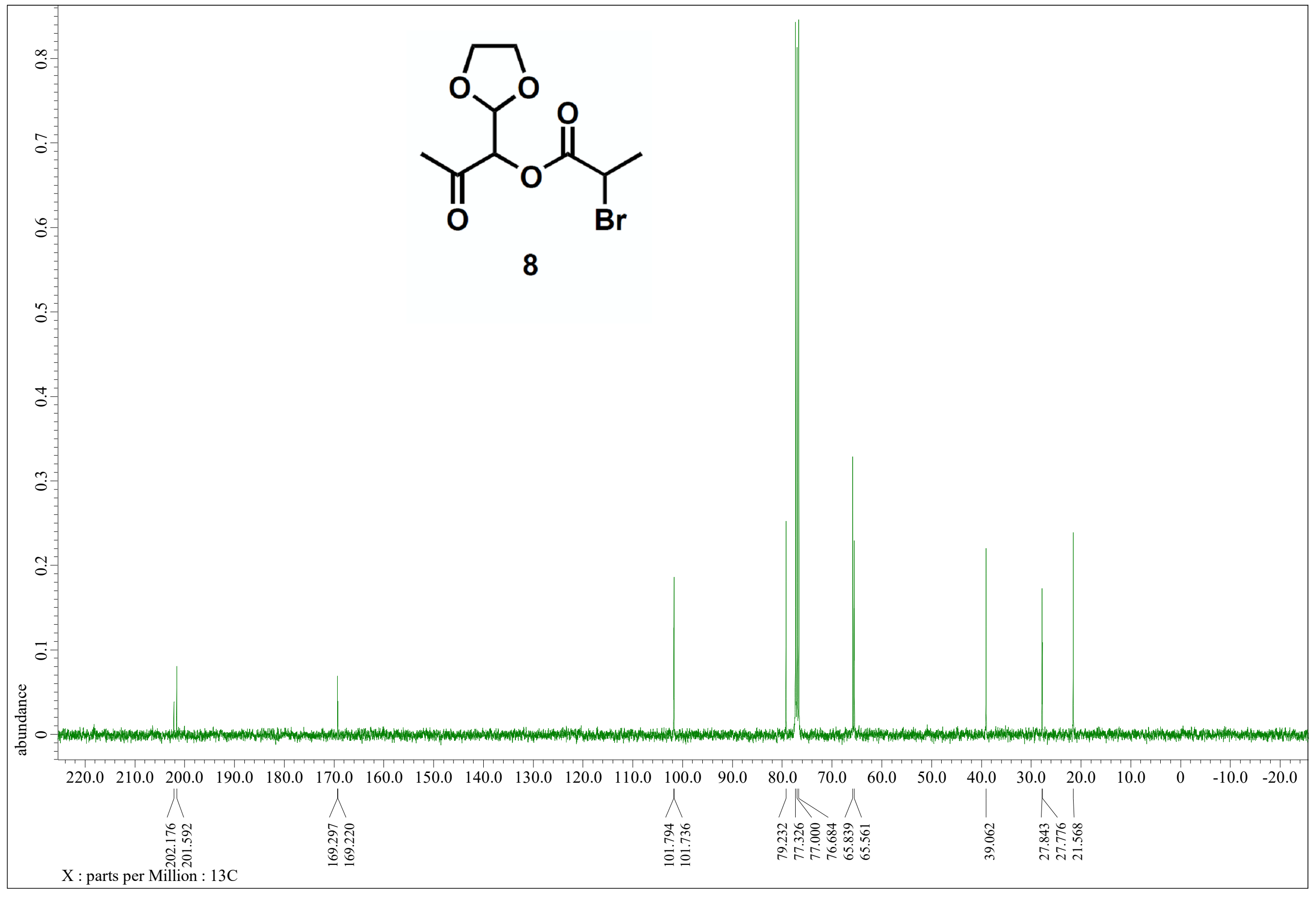




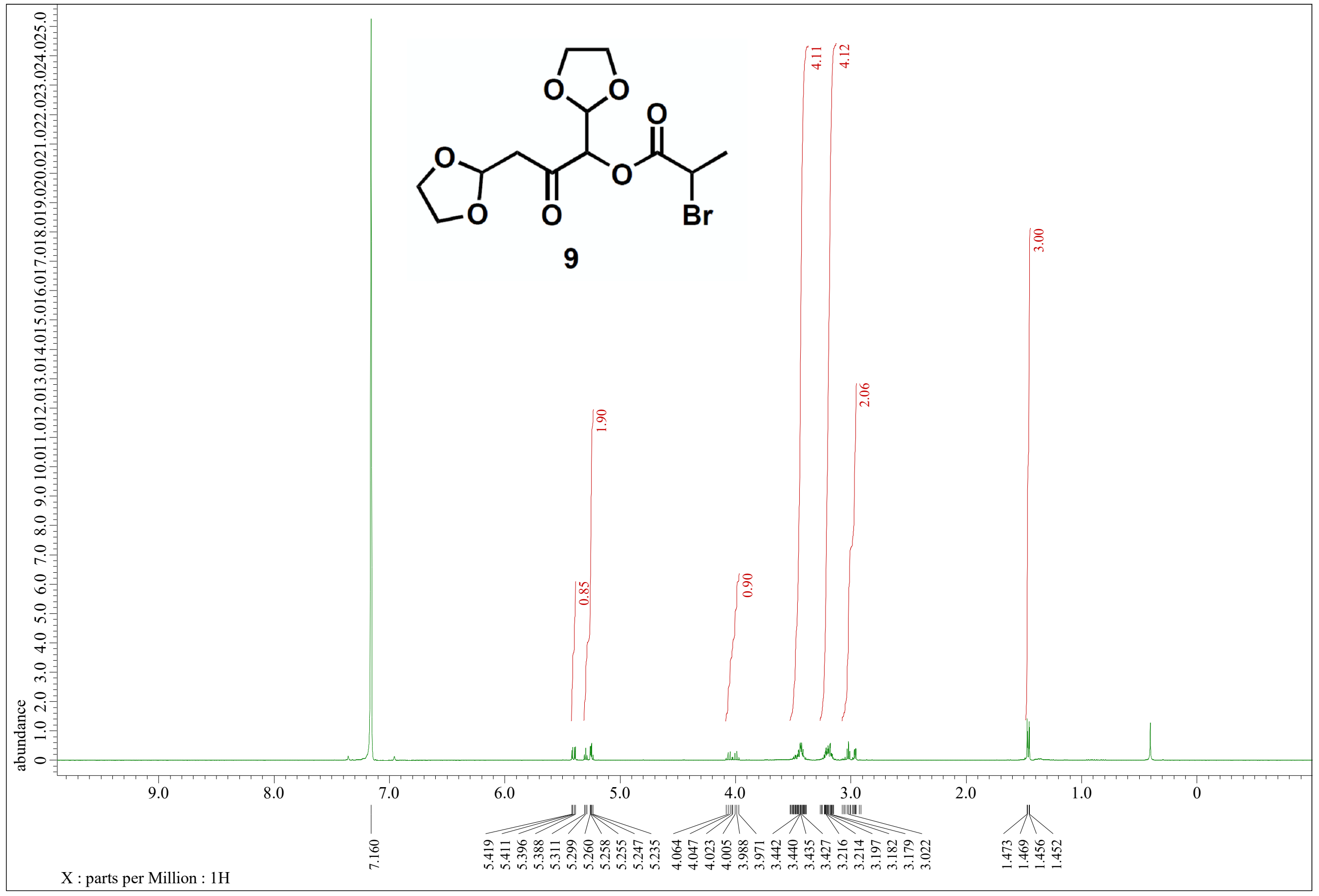




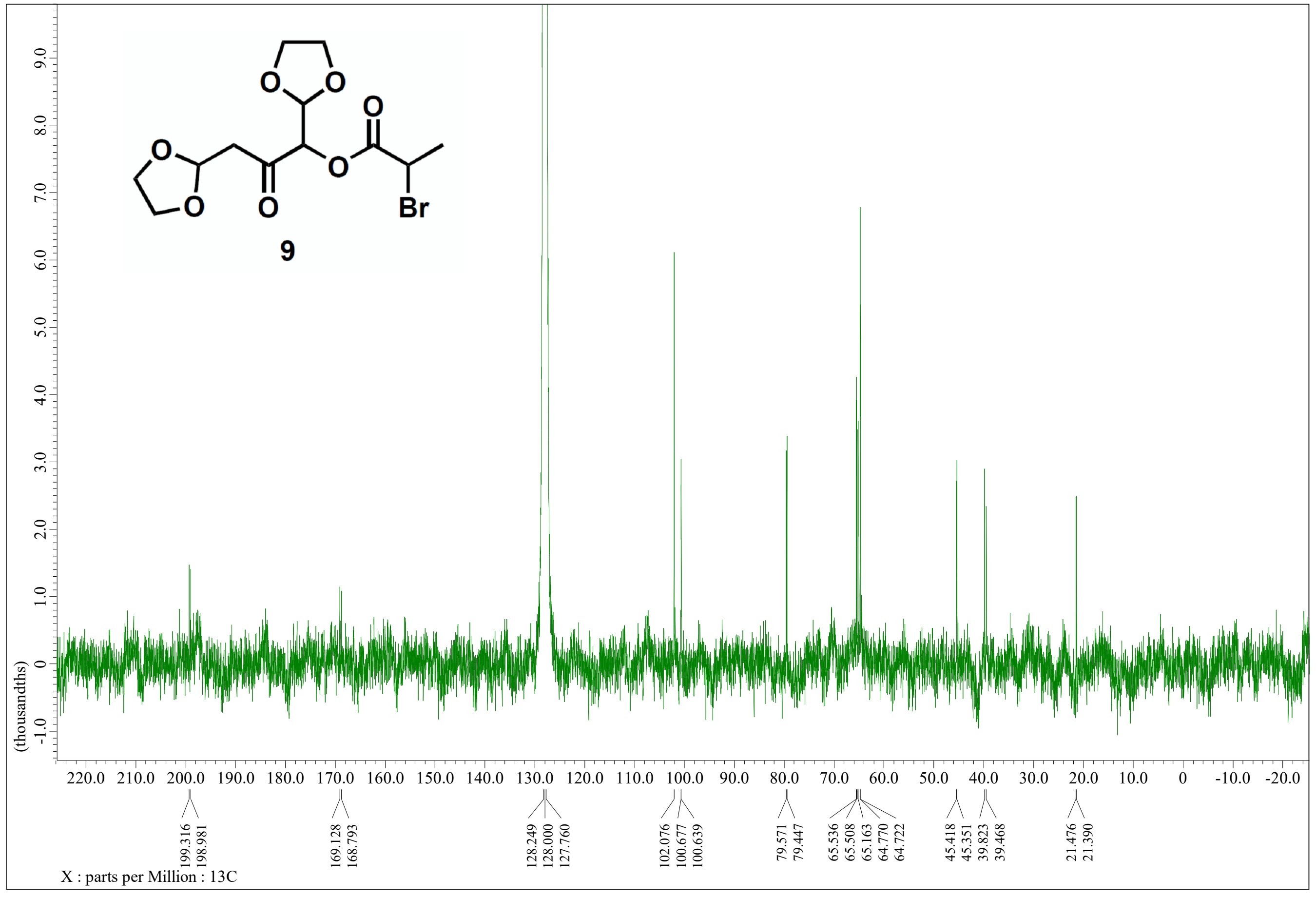




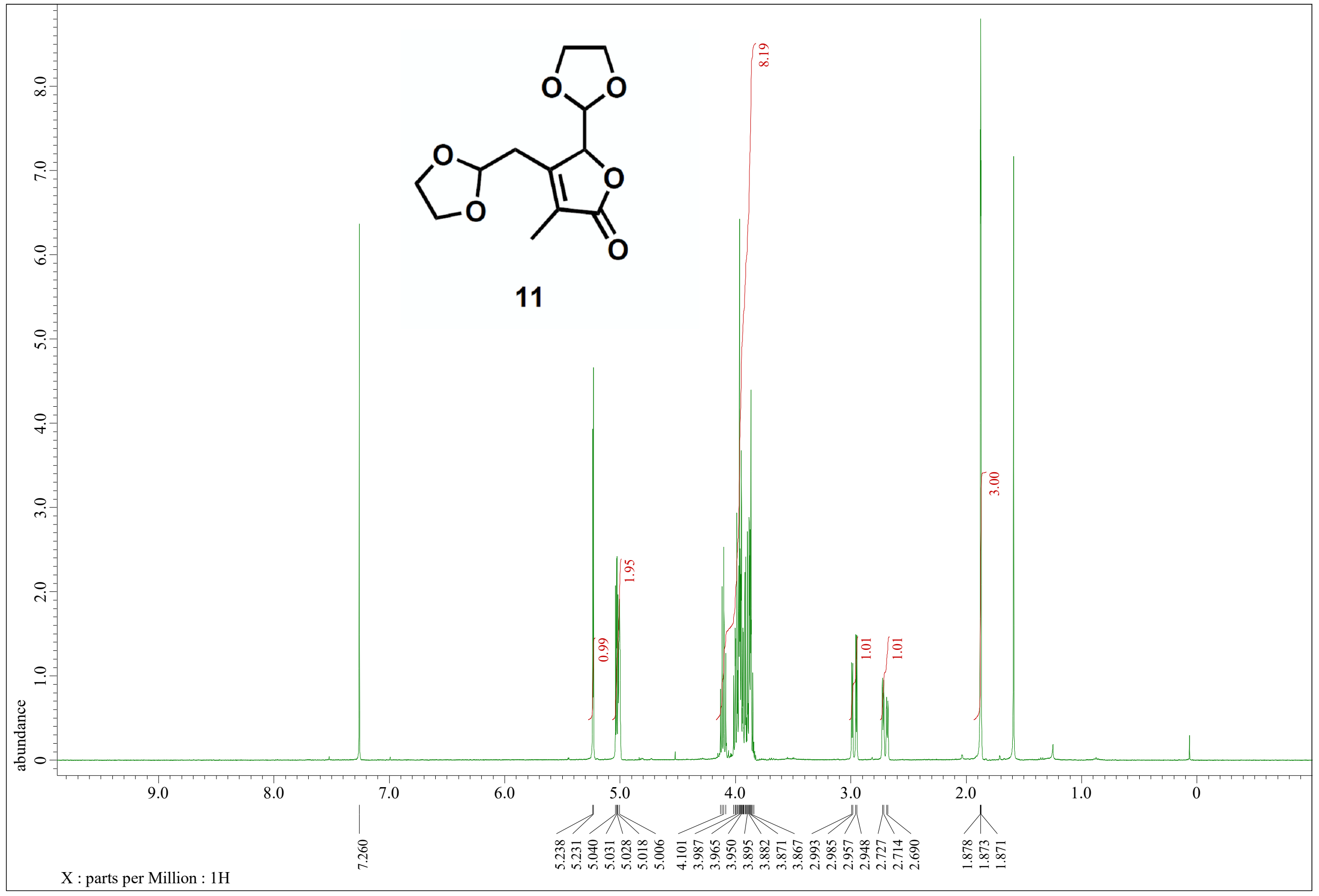




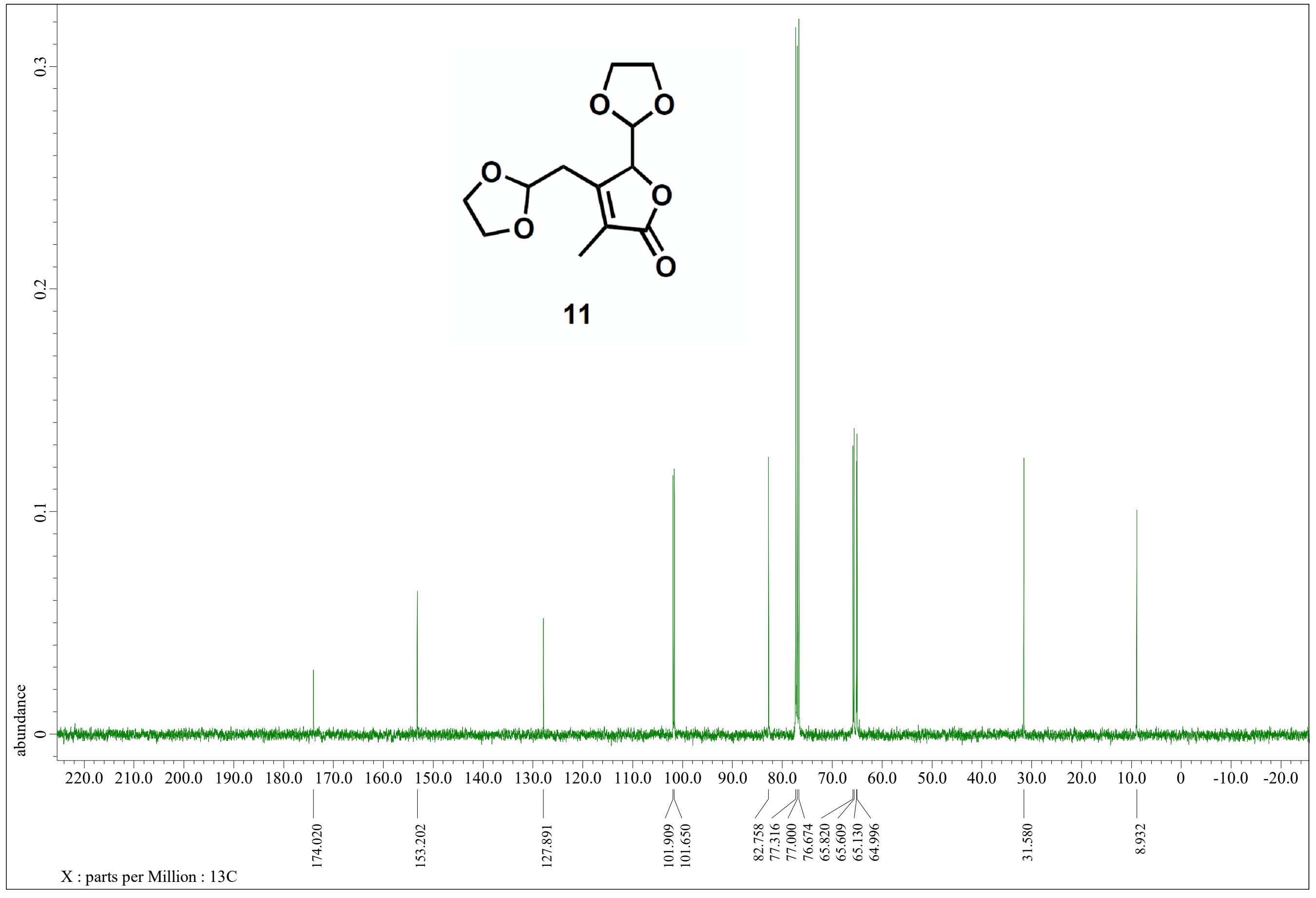




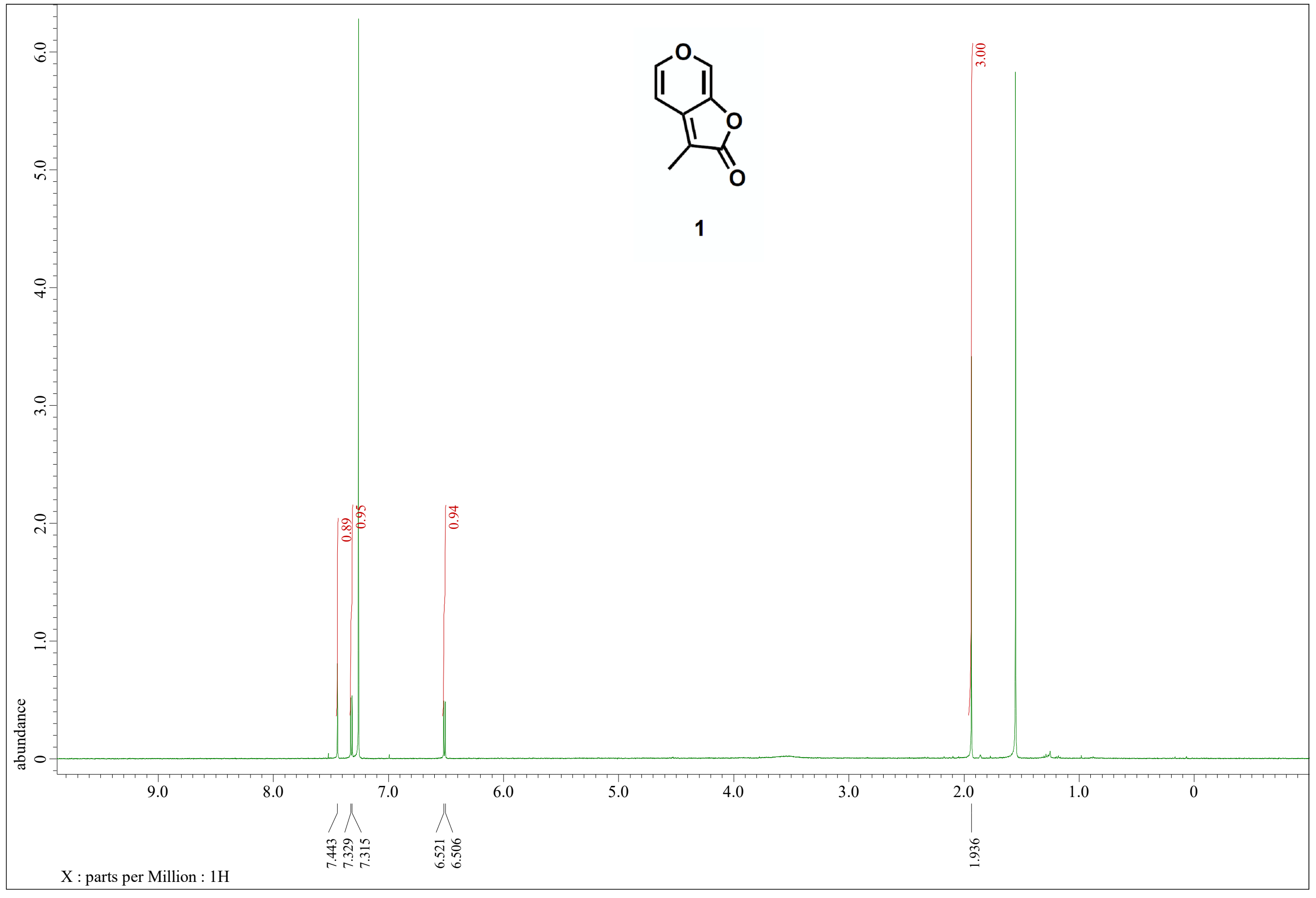




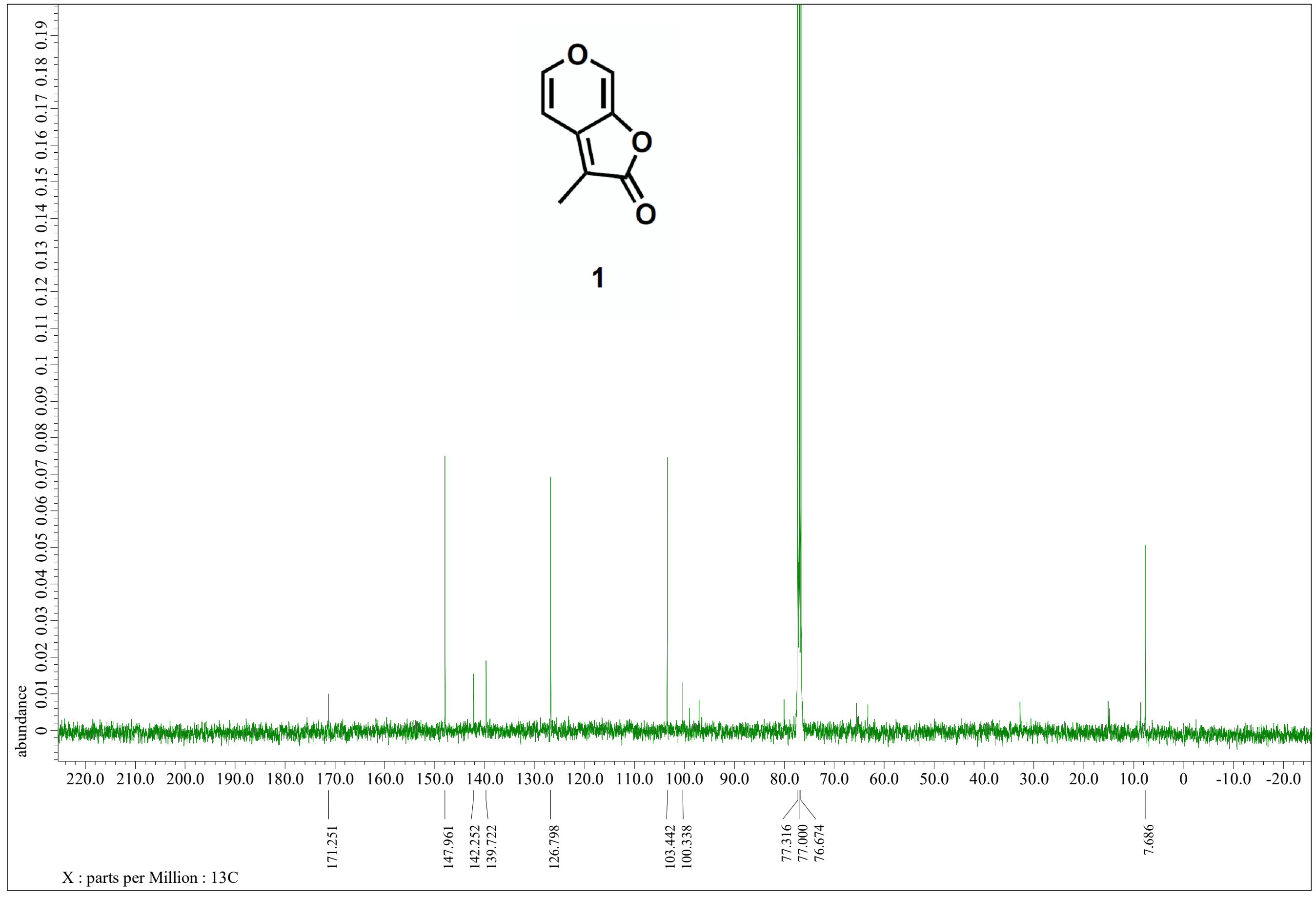

